\title{
Testing the Applicability of Six Macroscopic Skeletal Aging Techniques on a Modern Southeast Asian Sample
}

\author{
Timothy P. Gocha a,b, ${ }^{\text {, }}$ Megan E. Ingvoldstad ${ }^{\mathrm{c}}$, Adam Kolatorowicz ${ }^{\mathrm{a}}$, Meghan-Tomasita J. \\ Cosgriff-Hernandez ${ }^{c}$, Paul W. Sciulli ${ }^{a}$ \\ ${ }^{a}$ Department of Anthropology, The Ohio State University, Columbus, OH 43210, United States \\ ${ }^{\mathrm{b}}$ Division of Anatomy, The Ohio State University, Columbus, OH 43210, United States \\ ${ }^{\mathrm{c}}$ Central Identification Laboratory, Joint POW/MIA Accounting Command, Hickam AFB, HI \\ 96853, United States
}

\begin{abstract}
$\star$ This research was supported in part by an appointment to the Student Research Participation Program at the Joint POW/MIA Accounting Command/Central Identification Laboratory administered by the Oak Ridge Institute for Science and Education through an interagency agreement between the U.S. Department of Energy and JPAC/CIL.
\end{abstract}

* Corresponding author: The Ohio State University, Department of Anthropology, 4034 smith Laboratory, 174 W. 18 ${ }^{\text {th }}$ Avenue, Columbus, OH 43210, E-mail address: gocha.3@ osu.edu, Phone: 1-614-832-3266 


\section{ABSTRACT}

Most macroscopic skeletal aging techniques used by forensic anthropologists have been developed and tested only on reference material from western populations. This study examined the performance of six aging techniques on a known age sample of 88 Southeast Asian individuals. Methods examined included the Suchey-Brooks method of aging the symphyseal face of the os pubis (Brooks and Suchey 1990), Buckberry and Chamberlain's (2002) and Osborne et al.'s (2004) revisions of the Lovejoy et al. (1985) method of aging the auricular surface of the ilium, İşcan et al.'s $(1984,1985)$ method of aging the sternal end of the fourth rib, and Meindl and Lovejoy's (1985) methods for aging both lateral-anterior and vault sutures on the cranium. The results of this study indicate that application of aging techniques commonly used in forensic anthropology to individuals identified as Asian, and more specifically Southeast Asian, should not be undertaken injudiciously. Of the six individual methods tested here, the Suchey-Brooks pubic symphysis aging method performs best, though average age estimates were still off by nearly 10 years or greater. Methods for aging the auricular surface perform next best, though the Osborne et al. method works better for individuals below 50 years and the Buckberry and Chamberlain method works better for those above 50 years. Methods for age estimation from the sternal ends of the fourth rib and vault and lateral-anterior cranial sutures perform poorly and are not recommended for use on remains of Southeast Asian ancestry. Combining age estimates from multiple indicators, specifically the pubic symphysis and one auricular surface method, was superior to individual methods. Data and a worked example are provided for calculating the conditional probability that an individual belongs to a particular age decade, though overall age estimates may still be broad. 
KEYWORDS: Forensic Anthropology Population Data; Forensic Anthropology; Skeletal age estimation; Human aging variability; Conditional probability; Southeast Asia 


\section{Introduction}

When presented with an unknown set of human skeletal remains, a forensic anthropologist must attempt to discern sex, ancestry, age, stature, and any individualizing characteristics. Of these traits, estimation of age at death remains one of the most difficult tasks facing even experienced investigators [1]. While dental development is valuable for age estimation in subadults and epiphyseal union may be utilized through early adulthood, once skeletal maturity is reached age at death must be estimated through either histological quantification of skeletal/dental traits or the use of macroscopic methods based upon the deterioration of skeletal structures. Macroscopic techniques for age estimation are more commonly employed because they are quicker, cheaper, non-destructive, and do not require any specialized equipment. However, these techniques are not without criticism, as they often yield rather broad age estimates and older ages are regularly truncated into estimates of 50 or $60+$ years.

Compounding the concerns over accuracy of age estimation methods is the question of applicability of such methods to differing populations. Best practices in estimating age at death include using population-specific methods when they are available [2], though such standards are not available for many populations around the world. By necessity, age estimation methods are developed on osteological reference samples of known demographics [3], often limited to those of European and African American descent. The application of such methods to different populations requires an assumption of uniformitarianism - that age-related morphological alterations are the same in populations across time and geography [4]. Such an assumption, however, may be intrinsically flawed because while senescence itself is a universal phenomenon, 
the manner in which each individual experiences it is determined by a complex set of interactions between genetics, environment, and culture [5].

This study sought to test the uniformitarian assumption of skeletal aging through a comprehensive approach, applying six macroscopic age estimation methods to an identified sample of Southeast Asian origin. Specifically we investigated the Suchey-Brooks method of aging the symphyseal face of the os pubis [6], Buckberry and Chamberlain's [7] and Osborne et al.'s [8] revisions of the Lovejoy et al. [9] method of aging the auricular surface of the ilium, İscan et al.'s [10-11] method of aging the sternal end of the fourth rib, and Meindl and Lovejoy's [12] methods for aging both lateral-anterior and vault sutures on the cranium. These methods were chosen because they represent elements from throughout the human skeleton, include some of the methods most commonly employed by forensic anthropologists, and none except the Suchey-Brooks method have ever been tested in a skeletal sample of Asian origins.

\section{Materials and Methods}

The material used for this study was from the osteology collection housed at Khon Kaen University School of Medicine in Thailand. The collection contains approximately 800 skeletons, and demographic information was recorded for each individual at the time of body procurement. The majority of individuals were born during the twentieth century, though some of the earliest decedents (less than $2 \%$ of the collection) were born in the late nineteenth century. Most of the collection was built from a body donation program, although some material is derived from individuals who were Thai military, monks, or unclaimed bodies. The majority of individuals were lifelong inhabitants of the rural Isaan region of northeast Thailand although some may have distant Laotian or Chinese ancestry (Mann RW, pers. comm., 03/06/2014). 
To minimize bias in the data structure, an age/sex balanced data collection protocol with an equal number of males and females from each decade of life was desired. Unfortunately, the demographic structure of the collection made this impossible. For example, there are only four females included in the 20-29 age range, which is fewer than in any other age range of the sample. These four females, though, were only four from this age range present in the Khon Kaen skeletal collection at the time data was collected. In total, 88 individuals of known age were examined (Table 1). A larger sample would have been desirable, but unfortunately the authors' had less than one week for data collection. Furthermore, a larger sample would have exacerbated differences in sample sizes for each age cohort. Males ranged from 20-78 years $($ mean $=48.3, \mathrm{SD}=17.6)$, while females ranged from $24-97$ years $($ mean $=52.9, \mathrm{SD}=17.6)$; the sexes did not significantly differ in age distributions (Mann-Whitney $U$-test, $p=0.293$ ).

Table 1 - Age and sex distribution of the study sample

\begin{tabular}{cccc}
\hline Known age (years) & Male $(\boldsymbol{n})$ & Female $(\boldsymbol{n})$ & Total $\boldsymbol{n}$ \\
\hline $\mathbf{2 0 - 2 9}$ & 9 & 4 & 13 \\
\hline $\mathbf{3 0 - 3 9}$ & 7 & 7 & 14 \\
\hline $\mathbf{4 0 - 4 9}$ & 7 & 10 & 17 \\
\hline $\mathbf{5 0 - 5 9}$ & 7 & 7 & 14 \\
\hline $\mathbf{6 0 - 6 9}$ & 7 & 9 & 16 \\
\hline $\mathbf{7 0 +}$ & 7 & 7 & 14 \\
\hline Total $\boldsymbol{n}$ & 44 & 44 & 88 \\
\hline
\end{tabular}

To minimize bias in data collection, observers collecting data were blinded to known age of decedents in the skeletal collection. However, sex was known in order to utilize sex-specific phase descriptions of the sternal rib method and sex-specific images of the Suchey-Brooks method. All skeletal aging methods investigated were applied as detailed in the original publications. For the Suchey-Brooks, Osborne et al., and İşcan et al. methods, this meant assigning the skeletal element under investigation into a phase, while composite scores were calculated for elements using the Buckberry and Chamberlain and Meindl and Lovejoy methods. 
For the Buckberry and Chamberlain method, the composite score was then translated into a stage score. Differences between left and right pubic symphyses [13], auricular surfaces [14], and sternal ends of the fourth rib [15] have been shown to be insignificant, therefore methods were applied to either side while taking care to avoid any damaged or pathological elements. Because of differential preservation of some individuals, all aging techniques could not be applied to every individual in the sample. Data was collected by three of the authors, each of whom had considerable prior experience with the application of the aging methods tested. Each data collector analyzed a set of human remains in its entirety, meaning one observer applied all six aging techniques to a single set of remains. Admittedly this approach may result in some level of partiality for an observer, where having assigned an age by one method might influence the age assigned in applying the subsequent aging methods. However, this approach was still adopted in this research not only for its efficiency, but also because it reflects many real-world analytical settings wherein an observer is responsible for examining an entire set of remains, rather than a separate observer being responsible for applying a separate aging technique.

The mean age reported for each phase/stage or composite score in the original literature was then used as a point age estimate for each individual. However, crania that demonstrated either no suture closure (fully open) or complete suture obliteration (fully closed) were not assigned a point age estimate as Meindl and Lovejoy [12] suggest an age range with these conditions rather than providing a mean age. Point age estimates derived from each method were compared to known age at death through calculations of bias, inaccuracy, and correlation, which are common when testing the accuracy of aging methods in different populations [e.g. 13, 16-18]. Bias is the mean over- or under-estimation of age [ $\Sigma($ estimated age - known age $) / \mathrm{N}]$. Inaccuracy is the mean absolute error of the estimation $[\Sigma \square$ estimated age- known age $\square / \mathrm{N}]$ and 
therefore does not account for the directionality of error in age estimation. Spearman's rank correlation coefficients were also calculated to compare estimated age to known age. Furthermore, the proportion of cases in which the known age was within \pm two standard deviations of the mean age reported for a phase/stage/composite score was also evaluated [20].

In addition to individual techniques, three different combination strategies were assessed: the first averaged point age estimates from all six methods, the second averaged point estimates from the three pelvic aging methods, and the third averaged the Suchey-Brooks age estimate and the Osborne et al. age estimate if the pubic symphysis was found to be in phases I-IV, but averaged the Suchey-Brooks age estimate and the Buckberry and Chamberlain estimate if the pubic symphysis was found to be in phase V-VI. This third combination derives from the results obtained in this study (see Results). The average ages calculated from these combination methods were also subjected to bias, inaccuracy, and correlation measures. Due to time constraints during data collection, measures of intra- and inter-observer error were not performed. All statistical analyses were completed using Microsoft Excel 2010 (Microsoft Corporation, Redmond, WA) and SPSS Statistics 21.0 (IBM Corporation, Armonk, NY).

\section{Results}

The results of bias and inaccuracy by sex and decade for the Suchey-Brooks method for aging the pubic symphysis are given in Table 2. Overall the method performed better for males and younger individuals, demonstrated by lower values of bias and inaccuracy for these groups. Under 40 years there was no systematic over- or under-estimation of age, while above 40 years there was a tendency to underestimate age that was exacerbated in individuals over 50 years.

Table 2 - Bias and inaccuracy for the Suchey-Brooks method for aging the pubic symphysis 


\begin{tabular}{ccccccc}
\hline $\begin{array}{c}\text { Known age } \\
\text { (years) }\end{array}$ & $\boldsymbol{n}$ & Bias & Inaccuracy & $\boldsymbol{n}$ & Bias & Inaccuracy \\
\hline $\mathbf{2 0 - 2 9}$ & 9 & 1.4 & 2.9 & 4 & -6.2 & 6.2 \\
\hline $\mathbf{3 0 - 3 9}$ & 7 & 0.00 & 2.8 & 6 & 5.6 & 13.5 \\
\hline $\mathbf{4 0 - 4 9}$ & 7 & -4.1 & 4.8 & 10 & -3.4 & 6.2 \\
\hline $\mathbf{5 0 - 5 9}$ & 7 & -11.2 & 11.2 & 7 & -9.2 & 11.2 \\
\hline $\mathbf{6 0 - 6 9}$ & 7 & -16.7 & 16.7 & 7 & -12.8 & 12.8 \\
\hline $\mathbf{7 0 +}$ & 7 & -18.9 & 18.9 & 7 & -25.3 & 25.3 \\
\hline Overall & 44 & -7.8 & 9.2 & 41 & -8.7 & 12.5 \\
\hline
\end{tabular}

The results of bias and inaccuracy by sex and decade for the Osborne et al. method for aging the auricular surface are given in Table 3. Overall bias was lower for males than females, while the inaccuracy was the same for both sexes. Under 50 years there was a tendency to overestimate age for both sexes, while above 50 years, and most notably above 60 years, there was a tendency to underestimate age.

Table 3 - Bias and inaccuracy for the Osborne et al. method for aging the auricular surface

\begin{tabular}{ccccccc}
\hline $\begin{array}{c}\text { Known age } \\
\text { (years) }\end{array}$ & $\boldsymbol{n}$ & Mias & Inaccuracy & $\boldsymbol{n}$ & Bias & Inaccuracy \\
\hline $\mathbf{2 0 - 2 9}$ & 8 & 3.8 & 8.4 & 4 & 0.4 & 2.9 \\
\hline $\mathbf{3 0 - 3 9}$ & 7 & 10.9 & 11.9 & 7 & 13.5 & 13.6 \\
\hline $\mathbf{4 0 - 4 9}$ & 7 & 2.2 & 5.6 & 10 & 0.2 & 6.6 \\
\hline $\mathbf{5 0 - 5 9}$ & 7 & -4.4 & 7.5 & 7 & -8.3 & 8.3 \\
\hline $\mathbf{6 0 - 6 9}$ & 7 & -16.8 & 16.8 & 7 & -12.2 & 12.2 \\
\hline $\mathbf{7 0 +}$ & 7 & -23.4 & 23.4 & 7 & -27.8 & 27.8 \\
\hline Overall & 43 & -4.4 & 12.2 & 42 & -5.7 & 12.2 \\
\hline
\end{tabular}

The results of bias and inaccuracy by sex and decade for the Buckberry and Chamberlain method for aging the auricular surface are given in Table 4. Unique to this method was an overall tendency to overestimate age. Age was overestimated in males and females under 50 years, while above 50 years there was a slight tendency to underestimate age. Overall bias was lower for females, while overall inaccuracy was lower for males. 
Table 4 - Bias and inaccuracy for the Buckberry and Chamberlain method for aging the auricular surface

\begin{tabular}{ccccccc}
\hline $\begin{array}{c}\text { Known age } \\
\text { (years) }\end{array}$ & $\boldsymbol{n}$ & Males & Inaccuracy & $\boldsymbol{n}$ & Bias & Inaccuracy \\
\hline $\mathbf{2 0 - 2 9}$ & 8 & 18.0 & 19.1 & 4 & 16.4 & 16.4 \\
\hline $\mathbf{3 0 - 3 9}$ & 7 & 25.0 & 25.0 & 7 & 20.9 & 24.6 \\
\hline $\mathbf{4 0 - 4 9}$ & 7 & 15.7 & 16.6 & 10 & 10.0 & 15.7 \\
\hline $\mathbf{5 0 - 5 9}$ & 7 & 13.0 & 13.0 & 7 & -0.6 & 13.6 \\
\hline $\mathbf{6 0 - 6 9}$ & 7 & 0.6 & 5.8 & 7 & -1.6 & 10.7 \\
\hline $\mathbf{7 0 +}$ & 7 & -6.3 & 6.9 & 7 & -12.0 & 12.0 \\
\hline Overall & 43 & 11.2 & 14.5 & 42 & 5.1 & 15.4 \\
\hline
\end{tabular}

The results of bias and inaccuracy by sex and decade for the İşcan et al. method for aging the sternal end of the fourth rib are given in Table 5. Overall bias and inaccuracy were lower for males than for females. Age was estimated rather well for males under 40 years, but above 40 years there was a systematic and increasing age underestimation. For females, the method also underestimated individuals above 40 years but estimated age rather well between 30-39 years.

Table 5 - Bias and inaccuracy for the İşcan et al. method for aging the sternal end of the fourth rib

\begin{tabular}{ccccccc}
\hline $\begin{array}{c}\text { Known age } \\
\text { (years) }\end{array}$ & $\boldsymbol{n}$ & Males & & & Females & \\
\hline $\mathbf{2 0 - 2 9}$ & 6 & 2.4 & 3.8 & 1 & -11.6 & 11.6 \\
\hline $\mathbf{3 0 - 3 9}$ & 6 & 0.2 & 8.4 & 5 & 3.5 & 6.4 \\
\hline $\mathbf{4 0 - 4 9}$ & 6 & -9.5 & 9.5 & 8 & -5.9 & 14.5 \\
\hline $\mathbf{5 0 - 5 9}$ & 5 & -10.1 & 10.1 & 4 & -12.8 & 17.4 \\
\hline $\mathbf{6 0 - 6 9}$ & 2 & -30.6 & 30.6 & 3 & -27.6 & 27.6 \\
\hline $\mathbf{7 0 +}$ & 5 & -29.0 & 29.0 & 4 & -37.5 & 37.5 \\
\hline Overall & 30 & -10.0 & 12.9 & 25 & -13.01 & 18.5 \\
\hline
\end{tabular}

The results of bias and inaccuracy by sex and decade for the Meindl and Lovejoy method of aging lateral-anterior cranial sutures are given in Table 6. Overall bias and inaccuracy were lower for males than for females. For males, age was overestimated under 40 years and 
underestimated above 40 years, though age estimates were decent between $40-49$ years. For females, age was overestimated under 30 years and underestimated above 30 years, though age estimates were close to known age between 30-49 years.

Table 6 - Bias and inaccuracy for the Meindl and Lovejoy method for aging lateralanterior cranial sutures

\begin{tabular}{ccccccc}
\hline $\begin{array}{c}\text { Known age } \\
\text { (years) }\end{array}$ & $\boldsymbol{n}$ & Males & Inaccuracy & $\boldsymbol{n}$ & Bias & Inaccuracy \\
\hline $\mathbf{2 0 - 2 9}$ & 3 & 8.9 & 8.9 & 2 & 9.1 & 9.1 \\
\hline $\mathbf{3 0 - 3 9}$ & 5 & 6.9 & 6.9 & 3 & -0.9 & 3.0 \\
\hline $\mathbf{4 0 - 4 9}$ & 6 & -3.7 & 5.2 & 8 & -0.7 & 5.7 \\
\hline $\mathbf{5 0 - 5 9}$ & 7 & -11.6 & 12.1 & 5 & -9.2 & 10.5 \\
\hline $\mathbf{6 0 - 6 9}$ & 7 & -17.3 & 17.3 & 9 & -17.9 & 17.9 \\
\hline $\mathbf{7 0 +}$ & 7 & -28.2 & 28.2 & 7 & -34.2 & 34.2 \\
\hline Overall & 35 & -10.3 & 14.2 & 34 & -12.9 & 15.5 \\
\hline
\end{tabular}

The results of bias and inaccuracy by sex and decade for the Meindl and Lovejoy method of aging cranial vault sutures are given in Table 7. Overall bias and inaccuracy were lower for males than for females. For males, age was overestimated under 40 years and underestimated above 40 years, though age estimates were decent between $40-49$ years. For females, age was overestimated under 30 years and underestimated above 30 years, though age estimates were close to known age between 30-49 years.

Table 7 - Bias and inaccuracy for the Meindl and Lovejoy method for aging cranial vault sutures

\begin{tabular}{ccccccc}
\hline $\begin{array}{c}\text { Known age } \\
\text { (years) }\end{array}$ & $\boldsymbol{n}$ & Bias & Inaccuracy & $\boldsymbol{n}$ & Bias & Inaccuracy \\
\hline $\mathbf{2 0 - 2 9}$ & 6 & 8.5 & 8.5 & 2 & 12.2 & 12.2 \\
\hline $\mathbf{3 0 - 3 9}$ & 5 & 10.54 & 10.54 & 3 & -1.5 & 2.5 \\
\hline $\mathbf{4 0 - 4 9}$ & 7 & -1.2 & 4.4 & 9 & -4.7 & 6.3 \\
\hline $\mathbf{5 0 - 5 9}$ & 7 & -11.5 & 11.5 & 5 & -15.3 & 15.3 \\
\hline $\mathbf{6 0 - 6 9}$ & 7 & -21.6 & 21.6 & 9 & -20.1 & 20.1 \\
\hline $\mathbf{7 0 +}$ & 7 & -34.0 & 34.0 & 7 & -39.6 & 39.6 \\
\hline
\end{tabular}




\begin{tabular}{lllllll}
\hline Overall & 39 & -9.4 & 15.7 & 35 & -15.9 & 17.8 \\
\hline
\end{tabular}

The results of bias and inaccuracy by sex and decade for age estimates derived from averaging point estimates from all methods tested are given in Table 8. Few individuals in the study sample had sufficient elements to apply all six methods, so this method of averaging had a significantly smaller sample size. The overall bias and inaccuracy were lower for males than for females, though for both sexes these measures were smaller than several of the individual aging methods tested. However, averaging only performed well on individuals between 40-49 years; there was significant overestimation of age for individuals under 40 years and significant underestimation for individuals above 49 years.

Table 8 - Bias and inaccuracy for age estimates derived from averaging point estimates from all methods

\begin{tabular}{ccccccc}
\hline $\begin{array}{c}\text { Known age } \\
\text { (years) }\end{array}$ & $\boldsymbol{n}$ & Males & Inaccuracy & $\boldsymbol{n}$ & Bias & Inaccuracy \\
\hline $\mathbf{2 0 - 2 9}$ & 2 & 8.6 & 8.6 & 0 & - & - \\
\hline $\mathbf{3 0 - 3 9}$ & 4 & 10.6 & 10.6 & 2 & 9.2 & 9.2 \\
\hline $\mathbf{4 0 - 4 9}$ & 5 & 0.3 & 2.0 & 5 & 0.4 & 2.2 \\
\hline $\mathbf{5 0 - 5 9}$ & 5 & -6.6 & 6.6 & 2 & -7.6 & 7.6 \\
\hline $\mathbf{6 0 - 6 9}$ & 2 & -17.1 & 17.1 & 4 & -13.9 & 13.9 \\
\hline $\mathbf{7 0 +}$ & 5 & -24.2 & 24.2 & 4 & -27.1 & 27.1 \\
\hline Overall & 23 & -5.5 & 11.2 & 17 & -9.3 & 12.3 \\
\hline
\end{tabular}

The results of bias and inaccuracy by sex and decade for age estimates derived from averaging the point estimates derived from the Suchey-Brooks, Osborne et al., and Buckberry and Chamberlain methods are given in Table 9. When combining point estimates for all pelvic aging methods, there was an overall lower bias for males and females. While inaccuracy was still near 10 years for both sexes, this was comparable to each individual method tested. Overall 
there was a tendency to overestimate ages under 50 years and underestimate ages above 50 years, though this combination method performed reasonably well for both sexes between 40-59 years.

Table 9 - Bias and inaccuracy for age estimates derived from averaging point estimates from three pelvic methods

\begin{tabular}{ccccccc}
\hline $\begin{array}{c}\text { Known age } \\
\text { (years) }\end{array}$ & $\boldsymbol{n}$ & Males & Inaccuracy & $\boldsymbol{n}$ & Bias & Inaccuracy \\
\hline $\mathbf{2 0 - 2 9}$ & 8 & 7.8 & 8.6 & 4 & 3.5 & 3.5 \\
\hline $\mathbf{3 0 - 3 9}$ & 7 & 12.0 & 12.0 & 6 & 13.0 & 15.0 \\
\hline $\mathbf{4 0 - 4 9}$ & 7 & 4.6 & 6.6 & 10 & 2.3 & 7.2 \\
\hline $\mathbf{5 0 - 5 9}$ & 7 & -0.9 & 4.8 & 7 & -6.0 & 8.1 \\
\hline $\mathbf{6 0 - 6 9}$ & 7 & -11.0 & 11.0 & 7 & -8.9 & 8.9 \\
\hline $\mathbf{7 0 +}$ & 7 & -16.2 & 16.2 & 7 & -21.7 & 21.7 \\
\hline Overall & 43 & -0.4 & 9.8 & 41 & -3.4 & 10.9 \\
\hline
\end{tabular}

The final combination method tested was an average age computed from the SucheyBrooks pubic symphysis method and a single auricular surface method. If an individual was assigned a Suchey-Brooks phase I-IV, age was averaged with the Osborne et al. auricular surface age estimate; if an individual was assigned a Suchey-Brooks phase V-VI, age was averaged with the Buckberry \& Chamberlain auricular surface age estimate. The results of bias and inaccuracy by sex and decade for age estimates from this method are given in Table 10. Overall this combination method performed slightly better for males than for females, and yielded the lowest inaccuracy and nearly the lowest bias of any method tested. There was a general tendency to overestimate ages under 50 years and underestimate ages above 50 years; however, with the exception of females between 30-39 years, this combination method estimated age reasonably well up to 69 years.

Table 10 - Bias and inaccuracy for age estimates derived from averaging point estimates from the Suchey-Brooks pubic symphysis method and a single auricular surface method

\begin{tabular}{ccccccc}
\hline & \multicolumn{3}{c}{ Males } & \multicolumn{3}{c}{ Females } \\
\hline $\begin{array}{c}\text { Known age } \\
\text { (years) }\end{array}$ & $n$ & Bias & Inaccuracy & $n$ & Bias & Inaccuracy \\
\hline
\end{tabular}




\begin{tabular}{ccccccc}
\hline $\mathbf{2 0 - 2 9}$ & 8 & 2.8 & 4.1 & 4 & -2.9 & 3.1 \\
\hline $\mathbf{3 0 - 3 9}$ & 7 & 5.4 & 6.6 & 6 & 10.5 & 12.9 \\
\hline $\mathbf{4 0 - 4 9}$ & 7 & 1.7 & 5.3 & 10 & 0.3 & 7.7 \\
\hline $\mathbf{5 0 - 5 9}$ & 7 & -0.4 & 5.9 & 7 & -3.3 & 9.9 \\
\hline $\mathbf{6 0 - 6 9}$ & 7 & -8.1 & 8.1 & 7 & -6.3 & 7.3 \\
\hline $\mathbf{7 0 +}$ & 7 & -12.6 & 12.6 & 7 & -18.6 & 18.6 \\
\hline Overall & 43 & -1.8 & 7.0 & 41 & -1.6 & 8.8 \\
\hline
\end{tabular}

Spearman's rank correlation coefficients were also calculated to assess the relationship between known age and estimated age for all methods tested, as was the proportion of cases in which known age was within \pm two standard deviation of the mean age for an assigned phase/stage/composite score (Table 11). Due to the smaller number of data points in each decade $(<10)$, correlation and \pm two standard deviation were applied to all individuals for a method rather than by decade as done previously.

Table 11 - Spearman's rank correlation coefficients and associated $p$-values for individual and combination aging methods, as well as the proportion of individuals where known age was within \pm 2 standard deviations (S.D.) of the reported mean age for the assigned phase/stage/composite score for each method tested.

\begin{tabular}{|c|c|c|c|c|c|c|}
\hline & \multicolumn{3}{|c|}{ Males } & \multicolumn{3}{|c|}{ Females } \\
\hline Method & $\mathbf{r}_{\mathrm{s}}$ & $\begin{array}{c}p- \\
\text { value }\end{array}$ & $\begin{array}{l}\text { Within } \\
\pm 2 \text { S.D. }\end{array}$ & $\mathbf{r}_{\mathrm{s}}$ & $\begin{array}{c}p- \\
\text { value }\end{array}$ & $\begin{array}{l}\text { Within } \\
\pm 2 \text { S.D. }\end{array}$ \\
\hline Suchey-Brooks pubic symphysis & 0.907 & 0.000 & $88.6 \%$ & 0.651 & 0.000 & $78.0 \%$ \\
\hline Osborne et al. auricular surface & 0.581 & 0.000 & $93.0 \%$ & 0.519 & 0.000 & $88.1 \%$ \\
\hline $\begin{array}{l}\text { Buckberry and Chamberlain auricular } \\
\text { surface }\end{array}$ & 0.582 & 0.000 & $81.4 \%$ & 0.643 & 0.000 & $76.2 \%$ \\
\hline İșcan et al. sternal end of fourth rib & 0.565 & 0.001 & $66.7 \%$ & 0.268 & 0.196 & $48.0 \%$ \\
\hline $\begin{array}{l}\text { Meindl and Lovejoy lateral anterior } \\
\text { cranial sutures }\end{array}$ & 0.456 & 0.006 & $71.4 \%$ & 0.489 & 0.003 & $67.6 \%$ \\
\hline $\begin{array}{l}\text { Meindl and Lovejoy vault cranial } \\
\text { sutures }\end{array}$ & 0.116 & 0.483 & $71.8 \%$ & 0.308 & 0.072 & $60.0 \%$ \\
\hline All methods averaged & 0.680 & 0.000 & & 0.738 & 0.001 & \\
\hline All pelvic methods averaged & 0.845 & 0.000 & & 0.647 & 0.000 & \\
\hline $\begin{array}{l}\text { Pubic symphysis and one auricular } \\
\text { surface averaged }\end{array}$ & 0.898 & 0.000 & & 0.707 & 0.000 & \\
\hline
\end{tabular}

\section{Discussion}


As previously mentioned, individual senescence is determined by a complex set of ongoing interactions between genes, environment, and culture, all of which contribute to a specific life history that may influence individual health, nutrition, and mechanical wear on the body [5]. These extrinsic and intrinsic influences on aging create a disconnect between chronological and physiological age in all bodily systems including the skeleton. As such, it is recognized that skeletal aging is a variable and nonlinear process [19], but this does not eliminate the need for age estimates in developing biological profiles of unknown remains in a medicolegal context.

While many of the standard macroscopic aging methods utilized in forensic anthropology can generally be said to meet the Daubert criteria [21], one may question if they still meet the criterion of having known or potential error rates when applied to individuals from populations other than those upon which the methods were developed. In an attempt to help establish known error rates, this study has applied six macroscopic aging techniques to an identified Southeast Asian sample.

When examining the performance of each of the six aging methods tested, it quickly becomes apparent that no single method works exceedingly well in the Asian sample. Bias reveals that nearly all methods tend to overestimate age in younger individuals while underestimating age in older individuals, often times severely so. For males, overall method bias is lowest for the Osborne et al. auricular surface aging method at -4.43 years, followed by the Suchey-Brooks pubic symphysis aging method at -7.81 years. For females, overall method bias is lowest with the Buckberry and Chamberlain auricular surface aging method at 5.06 years, followed by the Osborne et al. auricular surface aging method at -5.73 years. While these measures of bias are useful for indicating the direction of error in age estimation, they can be 
misleading if examined alone; if a method underestimates the ages of some individuals and overestimates others to roughly the same extent, bias may be close to zero despite the fact that age estimates are inaccurate. It is therefore pertinent to also examine measures of inaccuracy.

Overall method inaccuracy for males is lowest with the Suchey-Brooks method at 9.25 years, while all other methods have inaccuracy values greater than 10 years. For females, overall method inaccuracy is greater than 10 years for all methods; the Osborne et al. method had the lowest inaccuracy at 12.17 years, followed closely by the Suchey-Brooks method at 12.50 years. This means that even with the most accurate methods employed, age estimates from Asian skeletal remains may differ, on average, by 10 years from known age. When inaccuracy is examined by decade this is even more concerning, as age estimates may differ by as much as 40 years from known age.

The Spearman's rank correlation coefficients indicate estimated age from all methods positively correlates with known age and is statistically significant for males, excepting the cranial vault sutures method. The Suchey-Brooks method demonstrates the strongest relationship $\left(r_{s}=0.907\right)$, with all other methods falling well below this level. For females, all correlation coefficients are significant except for sternal rib ends and cranial vault sutures. As with males, the Suchey-Brooks method has the highest correlation for females $\left(r_{s}=0.651\right)$, though the Buckberry and Chamberlain auricular surface method is not far behind $\left(r_{s}=0.643\right)$.

According to the proportion of cases where the known age fell within \pm two standard deviations of the mean age for the assigned phase/stage/composite score, the Osborne et al. method performed the best with more than or nearly $90 \%$ of individuals falling in that range. This is followed by the Suchey-Brooks method with nearly $90 \%$ of males and nearly $80 \%$ of females within the range, while the Buckberry and Chamberlain method having just above $80 \%$ 
of males and more than $76 \%$ of females falling with the range. However, when comparing all individual methods to each other using measures of bias, inaccuracy and correlation, the SucheyBrooks method for aging the pubic symphysis performs best as it has the highest correlation values of any method for both males and females, the lowest or near lowest values of bias and inaccuracy. Correlations for both the Osborne et al. and Buckberry and Chamberlain methods of aging the auricular surface indicate these methods perform next best, though the Osborne et al. method though their high levels of inaccuracy are concerning. However, accounting for performance by decade, it can be seen that the Osborne et al. method performs better for individuals under 50 years, while the Buckberry and Chamberlain method performs better for individuals above 50 years. The lower proportion of cases falling within \pm two standard deviations, coupled with lower correlation, higher bias, and much higher inaccuracy values for the İscan et al. method and both Meindl and Lovejoy cranial suture methods indicate these aging methods do not perform well in this Southeast Asian sample.

Calculating an average age based on the point estimates from the six individual techniques provides more promising results than most of the individual methods, though the sample size for this combination method was smaller than for all other single or combination methods, and therefore these results must be viewed with some caution. With this combination method, the correlation coefficient for males is higher than all individual methods except Suchey-Brooks, while for females it is higher than all other methods. Bias from this combined method is lower than most individual methods for both sexes, though inaccuracy is not markedly better. Taking into consideration the poor performance of the sternal rib end method and both cranial suture methods individually, it is probable that they negatively influence the overall average age estimates. When these methods are excluded and average age is calculated from the 
point estimates from only the three pelvic aging methods, bias and inaccuracy improve for both sexes. Correlation coefficients also improve for males, but not females.

Considering the better performance of the Osborne et al. method in younger individuals and the Buckberry and Chamberlain method in older individuals, a final combination method was developed using the Suchey-Brooks pubic symphysis method and a single auricular surface method. If an individual was assigned a Suchey-Brooks phase I-IV, that age estimate was then combined with the Osborne et al. auricular surface age estimate, while the age estimate from an individual assigned a Suchey-Brooks phase V or VI was combined with the Buckberry and Chamberlain auricular surface age estimate. Overall this method performs the best in the Southeast Asian sample for both sexes, producing the second highest correlation coefficients of any single or combination method, the lowest inaccuracies of any method, and measures of bias well below that of any individual method at 3.5 years.

These data on bias, inaccuracy, and correlation help our understanding of how well the aging methods tested perform in a Southeast Asian population; unfortunately, though, they do not constitute a straightforward method for establishing how confident one can be in the age estimates produced. Such confidence can, however, be calculated through conditional probability. Lucy et al. [22] provide a thorough review of the mathematics behind conditional probability; a simplified example is presented here. Data necessary for calculating conditional probabilities of age are presented in Table 12, which provides frequency data for phase/stage scores assigned to individuals per decade of life. Considering the poor performance of sternal rib end and cranial suture methods, Table 12 includes data for only the pelvic methods tested in this study. These pelvic methods do not use sex-specific phase/trait descriptions; ergo, data for both sexes were combined. It is also important to have equal numbers of individuals observed for 
each method in Table 12, and therefore only individuals to whom all three pelvic methods could be applied are included. For an example of how to read this table, look at individuals aged 20-29 years-five are assigned a Suchey-Brooks phase I, two are assigned a phase II, and so on. Row totals indicate the total number of individuals contained in each known age group from the reference sample; for example there were 12 individuals aged 20-29 years.

Table 12 - Distribution of assigned phase/stage scores for three pelvic methods by known age

\begin{tabular}{|c|c|c|c|c|c|c|c|c|}
\hline \multicolumn{9}{|c|}{ Suchey- Brooks pubic symphysis phases } \\
\hline $\begin{array}{c}\text { Known } \\
\text { age } \\
\text { (years) }\end{array}$ & $\mathbf{I}$ & II & III & IV & $\mathbf{V}$ & VI & Total & \\
\hline $20-29$ & 5 & 2 & 3 & 2 & 0 & 0 & 12 & \\
\hline $30-39$ & 1 & 1 & 1 & 8 & 0 & 2 & 13 & \\
\hline $40-49$ & 0 & 0 & 1 & 10 & 5 & 1 & 17 & \\
\hline $50-59$ & 1 & 1 & 0 & 1 & 8 & 3 & 14 & \\
\hline $60-69$ & 0 & 0 & 0 & 1 & 10 & 3 & 14 & \\
\hline $70+$ & 0 & 0 & 0 & 0 & 5 & 9 & 14 & \\
\hline \multicolumn{9}{|c|}{ Osborne et al. auricular surface phases } \\
\hline $\begin{array}{c}\text { Known } \\
\text { age } \\
\text { (years) }\end{array}$ & 1 & 2 & 3 & 4 & 5 & 6 & Total & \\
\hline $20-29$ & 5 & 5 & 1 & 1 & 0 & 0 & 12 & \\
\hline $30-39$ & 0 & 2 & 0 & 9 & 0 & 2 & 13 & \\
\hline $40-49$ & 0 & 3 & 1 & 9 & 4 & 0 & 17 & \\
\hline $50-59$ & 0 & 1 & 0 & 8 & 4 & 1 & 14 & \\
\hline $60-69$ & 0 & 1 & 1 & 6 & 4 & 2 & 14 & \\
\hline $70+$ & 0 & 0 & 0 & 6 & 5 & 3 & 14 & \\
\hline \multicolumn{9}{|c|}{ Buckberry and Chamberlain auricular surface stages } \\
\hline $\begin{array}{c}\text { Known } \\
\text { age } \\
\text { (years) }\end{array}$ & $\mathbf{I}$ & II & III & IV & $\mathbf{V}$ & VI & VII & Total \\
\hline $20-29$ & 1 & 1 & 6 & 0 & 3 & 1 & 0 & 12 \\
\hline $30-39$ & 1 & 0 & 0 & 2 & 8 & 1 & 1 & 13 \\
\hline $40-49$ & 0 & 2 & 1 & 2 & 5 & 7 & 0 & 17 \\
\hline $50-59$ & 1 & 0 & 1 & 0 & 2 & 7 & 3 & 14 \\
\hline $60-69$ & 1 & 0 & 0 & 1 & 1 & 7 & 4 & 14 \\
\hline $70+$ & 0 & 0 & 0 & 0 & 2 & 5 & 7 & 14 \\
\hline
\end{tabular}


Calculating conditional probability allows the combination of multiple aging methods, though all aging methods included must be assumed to be conditionally independent given age. Assuming the pubic symphysis and the auricular surface to be conditionally independent given age is likely valid, though assuming the same for multiple methods assessing the auricular surface is likely invalid due to their consideration of the same morphological structure. Therefore, calculating conditional probability is recommended to follow the same combination method recommended above between the pubic symphysis and a single auricular surface method; an individual assigned a Suchey-Brooks phase I-IV will be combined with the Osborne et al. auricular surface method (Equation 1), while an individual assigned a Suchey-Brooks phase V-VI will be combined with the Buckberry and Chamberlain auricular surface method (Equation 2).

$\mathrm{p}($ age group $)=$

$\frac{\# \text { individuals in Suchey-Brooks phase }}{\text { row total }} \times \frac{\# \text { individuals in Osborne et al.phase }}{\text { row total }} \times \frac{\text { row total }}{\text { total \# individuals }}$

$\mathrm{p}($ age group $)=$

$\frac{\# \text { individuals in Suchey-Brooks phase }}{\text { row total }} \times \frac{\# \text { individuals in Buckerry and Chaimberlain stage }}{\text { row total }} \times \frac{\text { row total }}{\text { total \# individuals }}$

For example, a hypothetical individual with the phase/stage assignments of SucheyBrooks pubic symphysis V, Osborne et al. auricular surface 4, and Buckberry and Chamberlain auricular surface VI will have a Suchey-Brooks age estimate combined with that from the Buckberry and Chamberlain method. First a likelihood value is calculated for this individual for each known age category; likelihood takes into account the age distribution of the reference sample in a phase/stage and yields the probability of an individual with a particular phase/stage 
belonging to an age group. Equation 3 provides the calculated likelihood for the $40-49$ year age range for the hypothetical individual:

$$
\mathrm{p}(40 \leq \text { age } \leq 49)=\frac{5}{17} \times \frac{7}{17} \times \frac{17}{84}=0.0245(3)
$$

The value of $5 / 17$ is derived from the column of Table 12 that corresponds to the observed phase of the Suchey-Brooks method (here phase V) and the number of individuals (5) from the 40-49 year age group with this phase. This value is divided by the row total (17), which is the total number of individuals in the $40-49$ year age group. The value of $7 / 17$ is derived from the column that corresponds to the observed stage of the Buckberry and Chamberlain method (here stage VI) and the number of individuals (7) from the 40-49 year age group with this stage, which was again divided by the row total (17). The value of $17 / 84$ is the row total divided by the total number of individuals in the study sample represented in Table 12. The three fractional values are then multiplied to generate the likelihood value for that individual for that particular age group. This process is repeated to calculate a likelihood value for each age group, all of which are then summed together. The likelihood value for each age group is then divided by the sum of all likelihoods, which yields the conditional probability, or the probability the individual belongs to that particular age group. The results of these calculations for the hypothetical individual considered here are presented in Table 13.

Table 13 - Calculations of conditional probability of a hypothetical individual Age group (years) Likelihood Conditional probability

\begin{tabular}{ccc}
\hline $20-29$ & 0 & 0 \\
\hline $30-39$ & 0 & 0 \\
\hline $40-49$ & 0.0245 & 0.160 \\
\hline $50-59$ & 0.0476 & 0.311 \\
\hline $60-69$ & 0.0595 & 0.389 \\
\hline $70+$ & 0.0213 & 0.139 \\
\hline
\end{tabular}


From the conditional probabilities listed in Table 13 , there is $16.0 \%$ probability that the individual was between $40-49$ years, $31.1 \%$ probability that the individual was between $50-59$ years, $38.9 \%$ probability that the individual was between $60-69$ years, and $13.9 \%$ probability that the individual was older than 70 years. Although these conditional probabilities are spread across the older adult age range, they allow us to say that the individual was not younger than 40 years and was most likely between 50-69 years. One possible shortcoming of using the data in Table 13 to calculate conditional probabilities of age is the limited sample size of 84 individuals. A larger sample might more accurately depict the distribution of phases/stages produced by aging methods into age groups.

\section{Conclusions}

The results of this study indicate that application of aging techniques commonly used in forensic anthropology to individuals identified as Asian, and more specifically Southeast Asian, should not be undertaken injudiciously. Of the six individual methods tested here, the SucheyBrooks pubic symphysis aging method performs best though it is still plagued by high levels of bias and inaccuracy at older ages. Methods for aging the auricular surface perform next best, though the Osborne et al. method works better for individuals below 50 years and the Buckberry and Chamberlain method works better for those above 50 years. Methods for age estimation from the sternal ends of the fourth rib and vault and lateral-anterior cranial sutures perform poorly and are not recommended for use on remains of Southeast Asian ancestry. Generating estimated ages from averages of all six aging methods performed better than most individual methods, though two different approaches to combining only pelvic indicators performed much better than the overall combination method. While measures of bias and inaccuracy help 
establish known error rates for the individual method tested in this Southeast Asian population, they are not direct measures of confidence in age estimates. Data and a worked example are provided for calculating conditional probabilities that permit one to assess the degree of confidence that an individual belongs to a particular age group, though overall age estimates may still be broad. The errors associated with age estimation in this Southeast Asian population are still considerable and may be attributed to the nonlinear process of aging and differences between the sample population and populations from which the methods were originally derived. Further research on known-age Asian material is recommended to more fully examine differences in the aging process between Western and Asian populations, and further examine different combinations of aging methods that may prove useful. This may permit further refinement of existing methods for application in Asian skeletal material or the development of new population-specific methods. 


\section{References}

1. U. Wittwer-Backofen, J. Buckberry, A. Czarnetzki, S. Doppler, G. Grupe, G. Hotz, A. Kemkes, C. Larsen, D. Prince, J. Wahl, A. Fabig, S. Weise, Basics in paleodemography: A comparison of age indicators applied to the early Medieval skeletal sample of Lauchheim, Am. J. Phys. Anthropol. 137 (2008) 384-396.

2. Scientific Working Group for Forensic Anthropology, Age Estimation, issue date January 1, 2013, (2013), http://swganth.startlogic.com/Age\%20Rev1.pdf.

3. B.M. Usher, Reference samples: the first step in linking biology and age in the human skeleton. In: R. Hoppa, J. Vaupel (Eds.) Paleodemography: Age Distributions from Skeletal Samples. Cambridge Studies in Biological and Evolutionary Anthropology 31, Cambridge, Cambridge University Press, 2002, pp. 29-47.

4. R. Hoppa, Paleodemography: looking back and thinking ahead. In: R. Hoppa, J. Vaupel (Eds.) Paleodemography: Age Distributions from Skeletal Samples. Cambridge Studies in Biological and Evolutionary Anthropology 31, Cambridge, Cambridge University Press, 2002, pp. 9-28.

5. G. Harper, D. Crews, Aging, senescence, and human variation. In: S. Stinson, B. Bogin, R. Huss-Ashmore, D. O’Rourke (Eds.) Human Biology: An Evolutionary Perspective, New York, Wiley-Liss, 2000, pp. 465-505.

6. S. Brooks, J. Suchey, Skeletal age determination based on the os pubis: a comparison of the Acsádi-Nemeskéri and Suchey-Brooks methods. Hum. Evol. 5 (1990) 227-238.

7. J.L. Buckberry, A.T. Chamberlain, Age estimation from the auricular surface of the ilium: a revised method, Am. J. Phys. Anthropol. 119 (2002) 231-239.

8. D.L. Osborne, T.L. Simmons, S.P. Nawrocki. Reconsidering the auricular surface as an indicator of age at death, J. Forensic Sci. 49 (2004) 1-6.

9. C.O. Lovejoy, C., R.S. Meindl, T. Pryzbeck, R. Mensforth, Chronological metamorphosis of the auricular surface of the ilium: a new method for the determination of adult skeletal age at death, Am. J. Phys. Anthropol. 68 (1985) 15-28.

10. M.Y. İşcan, S.R. Loth, R.K. Wright, Age estimation from the rib by phase analysis: white males, J. Forensic Sci. 29 (1984) 1094-1104.

11. M.Y. İşcan, S.R. Loth, R.K. Wright, Age estimation from the rib by phase analysis: white females. J. Forensic Sci. 30 (1985) 853-863. 
12. R.S. Meindl, C.O. Lovejoy, Ectocranial suture closure: A revised method for the determination of skeletal age at death based on the lateral-anterior sutures. Am. J. Phys. Anthropol. 68 (1985) 57-66.

13. S.M. Hens, E. Rastelli, G. Belcastro, Age estimation from the human os coxa: a test on a documented Italian collection, J. Forensic Sci. 53 (2008) 1040-1043.

14. C.G. Falys, H. Schutkowski, D.A. Weston, Auricular surface aging: worse than expected? A test of the revised method on a documented historic skeletal assemblage, Am. J. Phys. Anthropol. 130 (2006) 508-513.

15. C. Yoder, D.H. Ubelaker, J.F. Powell, Examination of variation in sternal rib end morphology relevant to age assessment, J. Forensic Sci. 46 (2001) 223-227.

16. E. Baccino, D.H. Ubelaker, L-A.C. Hayek, A. Zerilli, Evaluation of seven methods of estimating age at death from mature human skeletal remains, J. Forensic Sci. 44 (1999) 931936.

17. A. Schmitt, Age-at-death assessment using the os pubis and the auricular surface of the ilium: a test on an identified Asian sample, Int. J. Osteoarchaeol. 14 (2004) 1-6.

18. K. Moraitis, E. Zorba, C. Eliopoulos, S.C. Fox, A test of the revised auricular surface aging method on a modern European population, J. Forensic Sci. 59 (2014) 188-194.

19. L. Klepinger, D. Katz, M. Micozzi, L. Carroll, Evaluation of cast methods for estimating age from the Os pubis, J. Forensic Sci. 37 (1992) 763-770.

20. T.L. Rogers, Skeletal age estimation. In: S. Blau, D.H. Ubelaker (Eds.) Handbook of Forensic Archaeology and Anthropology, Walnut Creek, Left Coast Press, Inc., 2009, pp. 208-221.

21. Daubert v. Merrell Dow Pharmaceuticals, Inc., 509 US 579 (1993).

22. D. Lucy, G. Aykroyd, A.M. Pollard, T. Solheim, A Bayesian approach to adult human age estimation from dental observations by Johanson's age changes, J. Forensic Sci. 41 (1996) 189-194. 